\title{
Alexandre Herculano e a construção do historiador ${ }^{*}$
}

\section{Alexandre Herculano and the historian's construction}

\author{
Michelle Fernanda Tasca \\ michelle.tasca@gmail.com \\ Doutoranda em História \\ Universidade Estadual de Campinas \\ Rua Ermelino Battisti, 64, Jardim Santa Teresa \\ 13311-052 - Itu - São Paulo \\ Brasil
}

\section{Resumo}

Este artigo busca apresentar a trajetória do historiador português Alexandre Herculano, sua formação e escolhas profissionais. Para tal objetivo, salientamos os anos iniciais de aprendizado e a importância da experiência do exílio, para então, adentrar ao seu desenvolvimento profissional e à junção dos afazeres de bibliotecário aos de historiador. Pretendemos demonstrar a conciliação entre as duas instâncias, ao mesmo tempo em que discutimos o processo de construção da historiografia oitocentista em que o historiador, para escrever sua síntese histórica, deveria antes de tudo reunir os materiais necessários através de incessantes buscas, catalogações e estudos de documentos que ainda não haviam sido adequadamente manuseados para servir a tais propósitos. Por fim, apresenta a forma como Alexandre Herculano foi lido ao longo dos anos e a mudança no viés crítico dos estudos analíticos.

\section{Palavras-chave}

Historiografia portuguesa; Historiografia do século XIX; Alexandre Herculano.

\begin{abstract}
This article aims to track the history of the Portuguese historian Alexandre Herculano, his education and career choices. For this purpose, we emphasize his early years of learning and the importance of his exile experience, before entering his professional development and the junction of his affairs as librarian and historian. We want to show the conciliation between the two stages, while discussing the construction process of the 19th century historiography - when a historian, in order to write his historic summary, should firstly gather the necessary materials through unremitting researching, cataloging and studying documents that had not been properly handled to serve such purposes. Finally, we show how Alexandre Herculano was read over the years and the change of the analytical studies' critique perspective.
\end{abstract}

\section{Keywords}

Portuguese historiography; Historiography of the nineteenth century; Alexandre Herculano.

Recebido em: 21/10/2016

Aprovado em: 26/6/2017

* Esse texto faz parte de uma pesquisa de doutorado desenvolvida com o apoio da Capes. 
O objetivo desse artigo não é elaborar uma biografia detalhada sobre Alexandre Herculano. Sua vida já foi muito abordada a partir dos mais diferentes aspectos, desde análises que partiam das características físicas do autor para entender sua personalidade, de obras que se centraram em momentos mais intensos de sua vida, a exemplo de sua juventude e os anos de exílio, e mesmo outras que tentaram entender os motivos para o seu retiro final em Vale de Lobos. Cabe-nos, entretanto, ressaltar alguns pontos da vida do historiador que parecem relevantes para construir a imagem do autor que nos propomos a estudar e ao mesmo tempo, compreender o processo que levou à escrita de suas obras históricas.

Sabemos que esse processo de interpretação da realidade vivida não nos garante acesso a uma realidade última, impossível mesmo de ser alcançada. Mas permite a significação da vida a partir de interpretações: "O sentido da vida é um puzzle que constantemente se completa e se refaz. Cada jogador que pretenda completá-lo irá introduzir peças que o implicarão a ele, ao seu meio e ao seu tempo" (MAURÍCIO 2005, p. 13). É nesse sentido que procuramos apresentar Alexandre Herculano. Para compreendê-lo é necessário pensá-lo como um grande quebra-cabeças, em que cada peça colocada acrescenta um ponto a mais de entendimento. Assim, para dar um sentido possível à sua existência optamos por algumas peças, ou seja, alguns momentos e alguns aspectos, que auxiliam nossa interpretação do autor de acordo com determinados interesses, no caso, sua relação com a história de Portugal.

Como o objetivo é, portanto, estudar o Alexandre Herculano como historiador, consideramos válido abordar sua formação intelectual de forma introdutória, apenas para nos situarmos em relação ao contexto do autor, lembrando assim a perspectiva de Quentin Skinner, de sinalização do contexto de inserção do autor para compreender seus atos de fala (SKINNER 2005). Em seguida, parece-nos impossível desligar os interesses e os trabalhos históricos de Herculano de sua profissão de bibliotecário, visto que, ao mesmo tempo em que foi atraído para o interior das bibliotecas por interesses na história de seu país, foram os acervos dessas mesmas instituições que permitiram a elaboração de sua densa obra histórica.

\section{Escolhas e experiências}

Nascido em Lisboa no ano de 1810, período em que Portugal andava às voltas com as invasões napoleônicas, Alexandre Herculano, conheceu desde cedo a ideologia liberal que o iria caracterizar em diversos momentos de sua vida. Já o pai do nosso autor foi um funcionário público que manteve certo contato com pessoas letradas e se interessou pelo liberalismo político. Não obstante, seus primeiros estudos foram feitos na Congregação de S. Felipe Néri no Hospício junto ao Paço Real das Necessidades, uma instituição de base religiosa, como era muito comum no período (SARAIVA 1977, p. 14). Apesar de não se ter certeza sobre as datas em que Herculano frequentou essa instituição - provavelmente durante a década de 1820 - sabe-se que estudou disciplinas de humanidades e língua latina, que o preparariam para um curso superior, ao qual não ingressou por problemas familiares (NEMÉSIO 2003, p. 144-145). 
Alexandre Herculano não fez parte da intelectualidade acadêmica que era muito proeminente em universidades portuguesas como a do Porto e a de Coimbra durante o século XIX, mas nem por isso seus trabalhos tiveram menor relevância. Ao invés de frequentar a universidade, ele cursou matemática na Escola Naval e participou da Aula do Comércio, que fora um curso prático criado pelo Marquês de Pombal para os filhos dos negociantes (GODINHO 2009, p. 474). Seguiu, dessa forma, por um caminho alternativo ao ensino superior, a exemplo de outras personalidades portuguesas que também estiveram fora do meio universitário, como Oliveira Martins. Tanto ele quanto Herculano, tiveram uma formação inicial para o comércio e apenas posteriormente ingressaram nos estudos históricos e literários. Como salienta Vitorino Magalhães Godinho: "Quer dizer que são homens que ficam em contacto com as realidades e que se abrem para uma problemática que era estranha à Universidade do seu tempo" (GODINHO 2009, p. 475). Nesse sentido, a Aula de Comércio teria sido preponderante nos interesses posteriores de Herculano pela história do $3^{\circ}$ Estado, ou seja, da classe comercial e do povo. Ao estudar a história do comércio e dos mercadores Herculano fez opções que talvez não fossem possíveis dentro do meio acadêmico, em que predominava a história política tradicional (GODINHO 2009, p. 475).

Em seguida, e aqui encontramos um ponto crucial na sua formação, Alexandre Herculano frequentou as aulas de Diplomática no Arquivo Real da Torre do Tombo entre os anos de 1830 e 1831 (CATROGA 1998, p. 57). Nesse curso, estudou paleografia, tornando-se apto para trabalhar com documentação manuscrita quando se viu empregado na Biblioteca do Porto, o que facilitou também a abordagem dos documentos necessários para a escrita de seus textos históricos. Foi nesse período que conheceu João Pedro Ribeiro, seus trabalhos em arquivos e seus estudos históricos (FERREIRA 1998 , p. 11). No entanto, apesar do curso frequentado na Torre do Tombo, a carreira de bibliotecário e posteriormente de historiador não fora uma ação planejada desde o princípio, já que esses conhecimentos o habilitariam tanto para a investigação histórica quanto para uma possível carreira no funcionalismo público (CATROGA 1998, p. 57).

O contato com círculos de pessoas intelectualizadas e influentes foi outro ponto importante na formação inicial do historiador. Participou dos salões lisboetas, dentre eles o mais importante da época, o salão da Marquesa de Alorna, onde foi iniciado ao romantismo e provavelmente também à língua alemã. Dentre as diversas personalidades que conheceu, estavam: António Feliciano de Castilho e Morgado de Assentis, antigo poeta da geração de Bocage (SARAIVA 1977, p. 14).

Foi o período dos debates sobre o classicismo e o romantismo, da recepção das novidades poéticas, novelísticas (o romance histórico) e filosóficas que vinham da Europa e, da Alemanha, influência pouco comum num país dominantemente francófilo. Para isso terá contribuído a sua facilidade para as línguas, pois é ponto assente que, embora sejam escassas as informações acerca do modo como adquiriu esses conhecimentos, falava 
e lia o espanhol, o francês, o italiano e o alemão, além de, logicamente, ser perito no latim (CATROGA 1998, p. 57).

Antes do início da Guerra Civil Portuguesa (1828-1834), Herculano já estava inserido no círculo letrado de Lisboa, teve contato com os principais debates intelectuais do período, conheceu o romantismo e algumas das vertentes literárias e filosóficas que se desenvolviam no restante da Europa, além de um considerável conhecimento de línguas estrangeiras.

No ano de 1828, D. Miguel foi declarado legítimo rei de Portugal, assumindo a regência, restaurando a monarquia absoluta e anulando todas as decisões decretadas por D. Pedro, então Imperador do Brasil. A anulação da Carta Constitucional outorgada em 1826, após a morte de D. João VI, foi o estopim para a eclosão das batalhas civis. Alexandre Herculano, com 21 anos, deixou os estudos e se uniu aos constitucionais contra os absolutistas.

Como consequência de suas posições políticas, Herculano foi exilado de Portugal, partindo inicialmente para Inglaterra e em seguida para a França. Essa viagem forçada para o exterior trouxe, no entanto, elementos importantes para sua formação. Além de ter aprofundado o conhecimento das línguas estrangeiras, frequentou diferentes bibliotecas e conheceu novos temas de discussões intelectuais e historiográficas. De acordo com Veríssimo Serrão, a "primeira raiz" da cultura de Herculano "desabrocha no exílio" (SERRÃO 1977, p. 41), ou seja, apesar de já conhecer um pouco sobre o romantismo pelas reuniões na casa da Marquesa de Alorna e sobre o liberalismo pelo próprio contexto político português, foi na Inglaterra onde sentiu o primeiro arrebatamento romântico e liberal. A França o fez aprofundar-se no liberalismo e nos autores dessa língua, dos quais já conhecia de antemão alguns da matéria histórica.

Herculano regressou para Portugal como combatente ativo dos "7500 bravos do Mindelo", que em 8 de julho de 1832, participaram do cerco na cidade do Porto. Como nos lembra Fernando Catroga, já conquistada a cidade, o soldado deu lugar ao poeta e ao homem de história (CATROGA 1998, p. 58).

\section{Biblioteca Porto e Real Biblioteca do Palácio da Ajuda}

O retorno de Herculano para Portugal se deu em uma época ainda muito conturbada da história nacional. Com a vitória do governo liberal, seguiu-se a extinção das ordens religiosas masculinas do país ${ }^{1}$, que eram detentoras das grandes bibliotecas. Como consequência, todas as obras passaram para a posse do Estado, que não possuía até então uma estrutura montada para armazenar e operar com essa quantidade de livros e documentação. Como agravante, as bibliotecas particulares dos religiosos também foram empossadas pelo poder público, dando origem a uma quantidade ainda maior de material a ser alocado e organizado.

Os primeiros trabalhos de Herculano com livros e documentos se iniciaram em 1832 nas "livrarias abandonadas"2 das ordens religiosas e, sobretudo, na

\footnotetext{
${ }_{1}^{1}$ As ordens religiosas masculinas foram extintas oficialmente pelo decreto de 28 de maio de 1834 , referendado por Joaquim António de Aguiar (CABRAL 2009/2010, p. 7).

2 Livrarias abandonadas - bibliotecas que integrava o patrimônio das ordens religiosas, que foram consideradas
} 
biblioteca sequestrada do Bispo do Porto, D. João de Magalhaes e Avelar. Nessa época, constam dois períodos distintos de trabalho, o primeiro como voluntário por cerca de oito meses e outro remunerado por mais quatro meses. Essas bibliotecas foram os primeiros fundos que constituíram a Real Biblioteca Pública do Porto (CABRAL 2009/2010, p. 10).

$\mathrm{Na}$ intenção de alocar esses acervos sob o poder do Estado, o governo liberal, através da Comissão Administrativa dos Conventos Extintos ou Abandonados, instalou livrarias e cartórios em diversos locais da cidade do Porto, que seriam reunidos posteriormente com a fundação da Biblioteca Pública. Como salienta Luís Cabral, o momento não era propício para a recolha e abrigo dessa grande quantidade de livros advinda das bibliotecas religiosas. No entanto, necessitando de uma forma de reunir e armazenar todo esse material, o governo liberal resolveu criar uma biblioteca pública na cidade do Porto (CABRAL 2009/2010, p. 7).

A biblioteca foi fundada pelo decreto de 9 de julho de 1833 sendo o primeiro bibliotecário, Diogo de Góis Lara de Andrade, nomeado já no dia seguinte (10 de julho de 1833) (CABRAL 2009/2010, p. 8). Alexandre Herculano foi um dos nomes cotados para ocupar o lugar de segundo bibliotecário, juntamente com José Rodrigo Passos e José Augusto Salgado. Na proposta de indicação dos nomes apresentada pela Câmara ao Governo, temos a passagem (CABRAL 2009/2010, p. 8):

Senhor. Em execução do Art. ${ }^{\circ} 7^{\circ}$ do Decreto de 9 do presente mez cabe a esta Comm.ão a honra e satisfação de propor a V.M.I. para segundo Bibliotecario da Real Biblioteca Publica em primeiro lugar a Alex.e Herculano de Carv. ${ }^{\circ}$ e Ar. $^{\circ}$, natural de Lisboa, de 23 anos de idade, porque, segundo ella é informada, é conhecedor das Linguas principaes, da Diplomacia [sic], emigrado, Voluntario do Regimento da Senhora D. Maria $2^{\mathrm{a}}$; entrou já em algumas acçoens e principiou a servir espontaneamente no arranjo de varias livrarias abandonadas em Novembro, e por ordem de V.M.I. em Março" (CABRAL 2009/2010, p. 8).

O período em que Herculano trabalhou na biblioteca do Porto foi crucial para sua carreira de historiador e também para a escrita de muitos de seus textos publicados a partir de então. A experiência adquirida com essa atividade, assim como o desenvolvimento de suas bases históricas, foi somada ao conhecimento dos manuscritos e impressos que o historiador foi recolhendo ao longo dos anos e que utilizou não só para a escrita de suas obras históricas como a História de Portugal (1846-1853), a História da origem e do Estabelecimento da Inquisição em Portugal (1854-1859), os Portugaliae Monumenta Historica (1856-1873), mas também para a escrita dos seus romances e narrativas literárias, e para a publicação de artigos em diversos periódicos.

O trabalho de montagem da nova biblioteca foi imenso, abrangendo a recolha, transporte e inventariação de uma enorme quantidade de livros, documentos e objetos da cidade do Porto e posteriormente de outras cidades

abandonadas na ocasião da entrada do exército liberal. Livrarias sequestradas - bibliotecas de pessoas particulares tidas por miguelistas e que, por essa razão, tiveram seus bens tomados pelo Estado (CABRAL 2009/2010, p. 10). 
portuguesas. Herculano participou de todo esse processo: inventariação dos livros e manuscritos das bibliotecas; louvações; transporte dos acervos; seleção e custódia das obras de maior valor; catalogação de impressos3; classificação do material utilizando o método de Brunet; além da participação na escolha do Convento de Santo António da Cidade para abrigar a biblioteca. Nesse processo, deveu-se ainda a Herculano o salvamento de muitas obras importantes da cultura portuguesa, como: a livraria de mão de Santa Cruz de Coimbra, o Diário de Vasco da Gama e a Crônica de D. Afonso Henriques, dentre outros (CABRAL 2009/2010, p. 12-13).

Alexandre Herculano permaneceu na Real Biblioteca Pública do Porto até 17 de setembro de 1836 , quando pediu demissão do cargo de $2^{\circ}$ bibliotecário por se recusar a jurar a Constituição de 1822. Essa atitude foi tomada em consonância com diversas personalidades importantes da cidade, inclusive o primeiro bibliotecário com quem trabalhava, Diogo de Góis Lara de Andrade (CABRAL 2009/2010, p. 14). O período em que Herculano passou no Porto, intensamente cercado por livros e documentos históricos foi crucial no aprofundamento da cultura e história portuguesa, resultando na publicação de diversos textos.

Ao abandonar o trabalho de bibliotecário no Porto, Herculano mudou-se para Lisboa onde passou a escrever ativamente para jornais e revistas. Assumiu a direção do Panorama em 1837, ao mesmo tempo em que contribuiu para diversos outros periódicos, tais como: O País, O Português, Diário do Governo, Repositório Literário e Revista Universal Lisbonense. Como Jacinto Baptista nos diz: "... sabemos, igualmente, que o futuro historiador fazia do jornalismo, nesta fase da sua vida, a ocupação permanente e que esta era a principal e (exceptuando talvez magros direitos de autor de um estreante nas Letras) fonte única de seus meios de subsistência" (BAPTISTA 1977, p. 16).

Em 1839, Herculano foi convidado pela rainha D. Maria II (por indicação de seu marido D. Fernando) para dirigir as bibliotecas reais da Ajuda e das Necessidades no lugar do Padre António Nunes, que estava adoentado e acabara de pedir a exoneração do cargo (SANTOS 1965, p. 7-8). Com a possibilidade de um empego estável e bem remunerado, Herculano deixou a direção do Panorama para se dedicar aos livros e aos estudos históricos que o novo ambiente de trabalho Ihe propiciava. Ele permaneceu como Bibliotecário-Mor de Sua Majestade até o final de sua vida em $1877^{4}$ e ao longo desse período, passou pelo reinado de D. Maria II e regência de D. Fernando II (1834-1853), e os reinados de D. Pedro V (1853-1861) e D. Luís I (1861-1889).

A Real Biblioteca da Ajuda não foi um simples local de trabalho para Alexandre Herculano. Desde a sua nomeação, ele trabalhou intensamente para a organização e complementação da biblioteca e fez disso sua vida. Não fosse sua atividade como bibliotecário, talvez seus trabalhos históricos não adquirissem a profundidade erudita e analítica que o historiador conseguiu imprimir em suas obras.

\footnotetext{
3 Esta catalogação foi feita entre 1835 e 1836, e originou a primeira geração de catálogos chamados de catálogos de Alexandre Herculano (CABRAL 2009/2010, p. 12).

4 Mesmo após mudar-se para Vale de Lobos, Alexandre Herculano continua no posto de bibliotecário-mor (SANTOS 1965, p. 38).
} 
Durante todos os anos em que efetivamente esteve presente na Biblioteca da Ajuda, Herculano morou ao lado dela, em uma casa que recebera juntamente com o novo cargo (SANTOS 1965, p. 8). Para termos uma noção da proximidade da casa do escritor e bibliotecário em relação ao seu local de trabalho, convém examinar duas plantas que apresentam a configuração da primitiva Biblioteca de Sua Alteza Imperial e Real (designação usada nos tempos de D. João VI e D. Pedro IV), a primeira datada de 1817 e a segunda de 1862 . Essas plantas apresentam as instalações do Palácio Real, conjuntamente com a biblioteca e a posição da casa de Herculano em relação a ela (SANTOS 1965, p. 14).

Mariana A. Machado Santos, descreve as duas plantas da seguinte forma:

As plantas são de $1817^{5}$ e 1862 , e nelas se vê em esboço, o actual Palácio Novo, e, na mais recente, a Patriarcal com a torre, as primitivas instalações da Biblioteca Real, o passadiço que ficou durante algum tempo a liga-la ao actual Palácio, percebendo-se nitidamente o corredor que ligava a habitação de Herculano (habitação que ainda hoje existe), às salas da Biblioteca velha, sem que ele necessitasse de sair à rua, e os jardins interiores, que a iluminavam. No entanto, a topografia da Biblioteca Velha está mais nítida na planta de 1817 (SANTOS 1965, p. 15).

$[\ldots]$

Saía de casa, pelo lado oposto ao do Largo da Ajuda, caminhava em frente, sem ter de ir á rua, e descendo uns pequenos degraus (que se distinguem na planta topográfica de 1822), podia penetrar na Biblioteca Real, e trabalhar sem que nada o incomodasse (SANTOS 1965, p. 21-22).

O padre oratoriano Vicente Ferreira de Sousa Brandão, também apresenta uma descrição da casa em relação à biblioteca:

[...] No fim dessas 3 Salas ha uma pequena Casa, que dá sahida p. a o quintal. Entre esta dita Casa e o Gabinete fomava o Sñr. Herculano hum paçadisso coberto, e claro para servir de comunicação entre a parte nova da Livraria, e a parte antiga, $\sim$ q he a actualmen.te existente: devendo por baixo deste paçadisso dar-se saida $\mathrm{p}$. a as duas $\mathrm{p}$. ter do seu Quintal (SANTOS 1965, p. 18).

Ou seja, tanto as plantas quanto as descrições dos autores apresentam a localização da residência de Herculano exatamente ao lado da biblioteca, o que permitia que o historiador tivesse acesso direto a ela sem precisar sair para a rua. Podemos imaginar, assim, a íntima relação estabelecida entre o escritor e seu local de trabalho, levado a uma intensa vivência de tantos anos rodeado dos materiais que foram objetos de sua profissão e também de seus interesses pessoais.

De acordo com Joaquim Veríssimo Serrão, Herculano fez da Biblioteca da Ajuda uma "grande oficina de investigação histórica". Para além das fontes manuscritas e impressas que permitiam os estudos históricos, ele recebia em sua residência a visita constante de diversos jovens que viriam a se tornar nomes importantes nas letras portuguesas como: Bulhão Pato, Rebelo da Silva,

\footnotetext{
${ }^{5}$ Apesar da planta de 1817 ser anterior ao período de trabalho de Herculano, percebe-se que a casa em que habitou estava integrada ao corpo da Livraria Real.
} 
Antonio Pedro Lopes de Mendonça e Oliveira Marreca. Com esses encontros, Herculano teria ajudado a formar muitos desses jovens (SERRÃO 1977, p. 62).

Em relação à atuação de Herculano nas referidas bibliotecas, sabemos que as recebeu em um estado de considerável desordem e deterioração. Não apenas os acervos encontravam-se caóticos, mas também o prédio estava bastante comprometido. Como suas funções compreendiam ainda as de uma espécie de inspetor das bibliotecas reais e do Real Gabinete de Física, anexo à Biblioteca da Ajuda, Herculano acabou por atuar em diversas frentes: "Mais do que um simples bibliotecário, orientava, dirigia, informava as licenças pedidas (mesmo as do diretor do Real Gabinete de Física) e tinha às suas ordens funcionários (oficiais bibliógrafos e moços da biblioteca) para os diversos serviços" (SANTOS 1965, p. 9).

Um dos problemas enfrentados por ele foi a grande saída e entrada de obras de forma desorganizada que, dentre outros motivos, eram reflexos das sucessivas mudanças no governo. Logo que Alexandre Herculano assumiu seu cargo, por exemplo, D. Maria mandara restituir os livros que anteriormente eram de posse dos liberais e solicitava-se também a retirada de muitos depósitos pertencentes a particulares ou a outras instituições: "O Pe. António Nunes começara por solicitar a retirada de muitos livros depositados: os do Duque da Terceira, os dos Marqueses de Sampaio e de Ponde de Lima, dos condes de Linhares e de Óbidos e do Visconde de Laborim, que impediam a boa arrumação da "Livraria Real", dizia ele" (SANTOS 1965, p. 6-7).

Diante de tantas saídas e entradas de obras, vindas de diversos fundos e mesmo de livrarias pertencentes a conventos extintos que haviam sido ali alocadas, já não se tinha clareza dos materiais que constituíam o acervo da Biblioteca Real (SANTOS 1965, p. 7). Em vista disso, Alexandre Herculano esmerou-se no arrolamento de todas as obras pertencentes a essa biblioteca, elaborando inclusive, listas de obras duplicadas, que posteriormente seriam vendidas ou trocadas por outras no intuito complementar o acervo real.

Em uma carta escrita em 1875 ao Administrador-Geral da Casa Real, Sebastião do Canto e Castro Mascarenhas, Herculano refere-se à organização e catalogação das obras feitas entre os anos de1840 e 1850, durante o reinado de D. Maria II:

A Bibliotheca Real, que se conservava em completa desordem, e as suas collecções manuscriptas a ponto de se arruinarem, foi nos anos de 1840 a 1850 ordenada e colocada methodicamente. Existe o seu catalogo em bilhetes, não se tendo reduzido a catalogo definitivo por falta de recursos materiais e pessoaes necessários para se obter esse fim (SANTOS 1965, p. 75).

Alexandre Herculano se encarregou ainda, da recolha de todo o material disperso que havia sido emprestado e não devolvido, desde livros, mapas, documentos até utensílios diversos. ${ }^{6}$ Uma das obras mais celebres a que o

\footnotetext{
${ }^{6} \mathrm{~A}$ Biblioteca da Ajuda possui em seu acervo uma série de ofícios nos quais Herculano procede dessa forma.
} 
historiador se dedicou em recompor, e que encontra-se até hoje nessa mesma biblioteca, foi o Cancioneiro da Ajuda. Trata-se de uma obra em pergaminho, datado do século XIII, escrito em galaico-português e que pertencera ao Colégio dos Nobres. Chegara ao seu conhecimento que a Biblioteca Nacional de Évora possuía diversas folhas soltas que haviam sido arrancadas, motivo que o fez requisitar esse material para recompor o Cancioneiro com a maior exatidão possível (SANTOS 1965, p. 23).

Solicitou também a devolução de muitas obras retiradas por particulares, embora muitas vezes sem sucesso, como os 44 volumes do Dicionário Geográfico de Portugal que havia sido requisitado pelo antigo diretor da biblioteca, o Conselheiro Doutor António Nunes de Carvalho, e armazenados na Torre do Tombo. Reclamou ainda: a "Fábrica que falece á cidade de Lisboa" de Francisco de Holanda, alguns volumes da "Symmicta Lusitanica" e o "Bulario de Clemente XIV" (SANTOS 1965, p. 23-24).

Apresentamos essas atividades detalhadas apenas para exemplificar a forma como Herculano procedia em sua atividade bibliotecária, e também para salientar o conhecimento minucioso do acervo que se encontrava sob sua responsabilidade. Conjunto esse, que servirá de base para a escrita de seus principais trabalhos.

Outro empreendimento que nos permite ter uma noção das obras pelas quais o autor se interessou e considerou importantes foi a troca, venda e aquisição de livros para o acervo da biblioteca, que possuía muitas duplicatas devido ao confisco ou alienação de bibliotecas diversas. A primeira venda documentada foi feita em 6 de junho de 1843 à Real Biblioteca de Munique e com o dinheiro arrecadado, Alexandre Herculano encomendou diversas obras na livraria Viúva Bertrand \& Filhos, sendo algumas delas vindas diretamente da França: Historia de la dominacion de los Arabes; Histoire d'Espagne de Rosseeuw Saint Hilaire; Institutions de l'Espagne e Essai sur la domination des Arabes en Espagne de Viardot; Theoria de las Cortes de Mercier (SANTOS 1965, p. 26).

A segunda venda que temos registrada foi feita para a Biblioteca Real de Berlim em 1844, e esses livros foram então trocados por 99 outros. Seguiramse mais cinco vendas de, respectivamente: 87, 98, 20, 166 e 55 volumes. Em 1866, Herculano realizou nova venda de 74 volumes ao livreiro de Paris J. Demichelis, de quem comprou por sua vez, 9 volumes da Monumenta Germaniae Historica. Em dezembro do mesmo ano vendeu mais 58 volumes a António Rodrigues (SANTOS 1965, p. 26-27). Essas são apenas as transações que ainda se encontram registradas, pode ter havido outras do mesmo teor que não chegam ao nosso conhecimento.

Algumas correspondências trocadas com os editores da família Bertrand ao longo dos anos também nos dão pistas semelhantes sobre os interesses bibliográficos do autor. Na carta datada de 14 de junho de 1843, que apresentamos abaixo, Herculano cita também a requisição de obras francesas aos editores, e pede especial atenção para a entrega dos quatro volumes "do Brunet" (DOMINGOS 2000). 
Illmo Snr.

Bertrand

Martyres

Illmo Snr.

Remetto a V. Sa a importancia dos livros: rogo a V. Sa declare no fim da Lista que - ficaram encommendados para França taes e taes obras - (que são aquellas que nós concordamos até perfazer a somma de 230 ou 232 mil reis) - Tambem me lembrou que não sendo precisos cá os livros ja, os podia o moço vir trazendo aos poucos, quando fosse a Lisboa. Assim tenha V. Sa. a bondade de Ihe arranjar um ballotezinho, para trazer hoje, e peço-lhe que venham nelle os 4 vol. do Brunet.

Sou de V. Sa.

Amº. e C. obrig. mo

A. Herculano

Ajuda 14 de Junho 1843 (DOMINGOS 2000, p. 109).

A opção de Herculano pela compra das referidas obras reflete seu próprio interesse e o que considerava importante dentre tantos assuntos do conhecimento. Nota-se uma predileção por livros contemporâneos, dos quais o acervo real estaria defasado, e também por muitas obras estrangeiras, sobretudo francesas. As obras encomendadas da França, e que foram citadas anteriormente, demonstram a grande relevância dada pelo historiador para a formação dos reinos espanhóis, já em consonância com seu grande tema de pesquisa, que seria a constituição do reino português. Importante salientar também, a compra da Monumenta Germaniae Historica que começou a ser publicada em 1826 e funcionou como uma compilação de estudos e textos medievais da história germânica.

Mariana A. Machado Santos estudou de forma aprofundada o período em que Herculano trabalhou nas bibliotecas reais de Lisboa. Como bibliotecária, percebemos que ela assume uma postura em defesa da atuação de Herculano como tal, ou seja, de acordo com a autora, ele fora um bibliotecário de carreira, dedicando-se fundamentalmente a este ofício e não utilizando seu cargo apenas para ter acesso aos acervos de acordo com seu interesse como historiador e investigador.

\begin{abstract}
Alexandre Herculano trabalhou muito naquelas salas, e sublinhamos muito porque temos ouvido a muitas pessoas dizer que a Herculano, como historiador, não Ihe devia importar o arranjo duma biblioteca; que ele era apenas investigador e homem de letras, e não um bibliotecário de carreira, e que, por isso, aquele cargo só lhe devia ter servido como meio, para melhor poder penetrar na intimidade dos recheios livrescos de valia, e permitir-Ihe escrever a História de Portugal e reunir os Portugaliae Monumenta Historica (SANTOS 1965, p. 15).
\end{abstract}

Apresentar a imagem de Alexandre Herculano como bibliotecário acima de quaisquer outras classificações que sua trajetória permite, é uma opção de representação. Como Herculano foi um autor já muito estudado, devido à sua importância na cultura portuguesa, a vastidão de sua obra fez com que fosse designado como historiador, literato, poeta, polemista, jornalista e mesmo como 
político em raros casos, além, é claro, de bibliotecário. Isso fez com que muitos estudiosos, que abordaram uma dessas facetas isoladamente, colocassem tal posição como sendo a dominante: "Representamos os outros para dar sentido à sua existência, para conferir sentido ao mundo, para falar do que somos e do que desejamos ser", escreve Carlos Maurício (MAURÍCIO 2005, p. 12).

A atividade de Herculano como bibliotecário não foi um meio para atingir seus fins como historiador, mas sua profissão e também uma etapa complementar que o levou a execução de seus trabalhos históricos. Não seria possível pensarmos nas "faces do poliedro" de Herculano, como designou Candido Beirante, de forma isolada, pois não compreenderíamos o autor. Os dois períodos de Herculano como bibliotecário foram fundamentais para a escrita da História de Portugal. Não fossem esses empregos talvez até tal obra (e outras do mesmo caráter histórico e literário) não tivesse sido escrita, ao menos não com mesma forma e substância.

\section{Alexandre Herculano ao longo dos anos}

Alexandre Herculano não foi apenas um historiador dedicado aos livros e documentos, as causas nacionais tiveram sempre um lugar muito importante em sua vida, e isso se refletiu na posição de destaque que, com o passar dos anos, ele acabou por ocupar dentro do imaginário português. Herculano tornouse uma personagem nacional. Não apenas suas obras têm sido muito estudadas, mas também sua vida pessoal deu origem a diversos estudos biográficos. 0 historiador foi muitas vezes elevado a uma espécie de pedestal, onde permaneceu como um intocável herói nacional por muito tempo. Mas não se tornou um herói aos moldes de D. Sebastião ou D. Affonso Henrique, guerreiros de armas nas mãos prontos para defender seu país. Herculano foi um herói de penas e livros. Defendia sua terra pela educação e pelo amor à pátria. Essa foi a imagem criada pela sociedade portuguesa nos finais do século XIX e início do XX, ou seja, nas décadas que seguiram à sua morte em 1877.

Como bem referiu Antonio José Saraiva, muito já foi escrito sobre a vida anedótica de Herculano: os anos heroicos em que lutou no exército liberal, seu trabalho com a imprensa e como bibliotecário real, suas obras memoráveis, o sofrimento com a morte do jovem príncipe, a desilusão com a vida pública e o derradeiro retiro para Vale de Lobos: "É preciso, enfim, descê-lo do pedestal onde o imobilizaram, e recolocá-lo no seu meio e no seu tempo, como um homem vivente entre os outros homens" (SARAIVA 1977, p. 12).

[...] um autor deixa à sua volta um rasto indiciário (feitos de palavras e de obras, de actos e de comportamentos) que é e irá sendo apreendido e interpretado de inúmeras maneiras. Essas interpretações serão por sua vez reinterpretadas na construção de novas interpretações. Forma-se assim uma trajectória de recepção. E esta é sempre uma interacção entre diversas dinâmicas interpretativas (MAURÍCIO 2005, p. 12).

A partir desse rasto indiciário deixado por Herculano, suas obras e seus feitos, é que ele foi sendo interpretado, construído e reconstruído, por décadas 
a fio até que hoje nós podemos olhar para trás e perceber as múltiplas faces dadas ao autor. Em vista da imensa quantidade de estudos sobre o tema, alguns autores foram considerados mais significativos seja pela densidade das análises ou pela permanência dessas obras como referências para escritores que vieram depois. São alguns deles: Vitorino Nemésio (1901-1978), Antonio José Saraiva (1917-1993), Vitorino Magalhães Godinho (1918-2011), Joaquim Barradas de Carvalho (1920-1980), Jorge Borges de Macedo (1921-1996), Joaquim Verissimo Serrão (1925), Candido Beirante (1937-2010), Fernando Catroga (1945).

No entanto, para além dos autores citados, muitos outros textos foram publicados desde a morte do historiador até os dias de hoje, sendo que muitos estudos recentes têm proposto novas abordagens e novos objetos de análise dentro da obra de Herculano. A partir da leitura da bibliografia básica sobre esse tema, conseguimos ter uma ideia de como o autor foi interpretado ao longo dos anos e da imagem de cidadão exemplar e historiador ideal que foi sendo construída, até que ele se tornasse uma espécie de mito dos estudos históricos portugueses.

Nas duas primeiras décadas que se seguiram à morte de Alexandre Herculano, percebemos que as obras referentes a ele são de cunho memorial, elogios ao homem e reconhecimento pelo legado. Como exemplo, podemos citar: À morte de Alexandre Herculano publicado em 1877 de Gomes Leal (1848-1921) e Elogio histórico do sócio de mérito Alexandre Herculano de Carvalho e Araújo em 1890, de Manuel Pinheiro Chagas (1842-1895).

Curiosamente, a década seguinte, que corresponde aos anos de 1898 a 1907, praticamente não apresenta publicações relevantes. As obras sobre Herculano começam a se tornar mais expressivas a partir do ano de 1910, ocasião do primeiro centenário de seu nascimento, quando aparecem de forma mais constante alguns textos críticos e analíticos, que estudam sua obra. No entanto, os elogios históricos ainda continuam presentes.

Os anos entre 1918-1927 são mais marcados por reedições de obras do que por estudos propriamente ditos. Não obstante, a partir da década de 1930 os textos analíticos retornam de forma preponderante. A partir desse período são publicadas análises mais aprofundadas e completas, sobretudo, na década de 1970, quando se comemorou o primeiro centenário de morte do autor.

Em relação às primeiras décadas da vida de Alexandre Herculano, a obra de Vitorino Nemésio, A Mocidade de Herculano até à Volta do Exílio (1934) é sem dúvida a mais completa e por isso, a mais frequentemente citada, mesmo por autores que escreveram estudos posteriores, a exemplo da "Introdução Biográfica" do livro Herculano e o Liberalismo em Portugal, escrita por Antonio José Saraiva, que cita muitas vezes da obra de Vitorino Nemésio (embora não exclusivamente, já que o autor elenca uma série de outras fontes de acordo com o tema tratado). Uma das características da obra de Nemésio é que ela objetiva um estudo da vida do autor, e não uma análise de sua obra. Como estudo biográfico, ela é muito mais detalhada e completa em referências documentais do que outras obras que tratam das primeiras décadas de vida do historiador. 
Para termos uma noção da forma como Herculano foi lido citamos duas obras que constam entre as mais representativas sobre esse tema: Ideias políticas e sociais de Alexandre Herculano de Joaquim Barradas de Carvalho e Herculano e o Liberalismo em Portugal, de Antonio José Saraiva.

As duas obras foram publicadas originalmente em 1949 e reeditadas na década de 1970, sendo que as Ideias políticas e sociais de Alexandre Herculano data de 1971 e Herculano e o Liberalismo em Portugal de 1977. Não por acaso, o enfoque dos dois textos é bastante semelhante, ou seja, eles são guiados por preceitos políticos, econômicos e sociais, refletindo uma tendência da historiografia portuguesa nesse momento. Por outro lado, é interessante notar o olhar dos autores sobre suas próprias obras a partir dos prefácios das reedições em que eles afirmam que já não possuem o mesmo posicionamento histórico da época da primeira edição, mas que fazer certas modificações alterariam seu caráter original. Joaquim Barradas de Carvalho, inclusive assume já uma outra visão sobre a história intelectual e Antonio José Saraiva afirma já ser uma pessoa muito distante da que foi quando escreveu o livro. Dessa forma, eles preocupam-se com as ideias ou o pensamento de Herculano, embora Carvalho se identifique mais com uma vertente marxista. Defendem que o autor a ser estudado deve ser visto em consonância com o seu meio e não isolado dele.

Os dois autores tentam promover a humanização da figura de Alexandre Herculano, o primeiro afirmando que sua obra não foi fruto de uma genialidade,

142 mas que deve ser vista em consonância com o momento vivido em Portugal e na Europa e o segundo afirmando que é necessário descer Herculano do pedestal que por muito tempo foi colocado.

No entanto, será que Saraiva consegue realmente tirar Herculano do pedestal? As análises e leituras críticas apresentadas nos capítulos cumprem essa função, embora na introdução biográfica o autor acabe por não se abster por completo de algumas formas de elogios, que muito provavelmente se justifiquem. Mas no geral a obra consegue se distinguir de autores do início do século que se contentavam apenas em exaltar as qualidades de Alexandre Herculano enquanto cidadão exemplar e modelo de ser português. O mérito, portanto, está em apresentar o historiador inserido em seu próprio meio e se posicionando em relação àquilo que o rodeava. Descer o autor do pedestal não implica em isentá-lo de seus méritos e esquecer suas qualidades, mas em observá-lo a partir de uma perspectiva crítica e procurar compreendê-lo a partir de diversas perspectivas que seriam limitadas pela simples exaltação meritória.

\section{Referências bibliográficas}

BAPTISTA, Jacinto. Alexandre Herculano: Jornalista. Amadora: Bertrand, 1977.

CABRAL, Luís. Alexandre Herculano: crónica breve de um bibliotecário. Cadernos BAD, n. 1/2, p. 7-15, 2009/2010. 
CATROGA, Fernando. Alexandre Herculano e o Historicismo Romântico. In: . História da História em Portugal (sécs. XIX-XX). Lisboa: Temas e Debates, 1998, p. 45-98.

COELHO, António Borges. Alexandre Herculano: vida, pensamento, obra. Lisboa: Presença, 1965.

DOMINGOS, Manuela. Herculano e os Bertrand: alguns inéditos. Revista Portuguesa de História do Livro, a. IV, n. 7, p. 87-118, 2000.

FERREIRA, Ema Tarracha. Introdução. In: HERCULANO, A. Lendas e narrativas.

2. ed. Seleção e introdução por Maria Ema Tarracha Ferreira. Lisboa: Biblioteca Ulisseia de Autores Portugueses, 1998, p. 7-66.

GODINHO. Vitorino Magalhães. Alexandre Herculano - O cidadão e o cientista. In: _. Ensaios e Estudos: uma maneira de pensar. Lisboa: Sá da Costa, 2009, p. 469-485. v. I.

HERCULANO, Alexandre. História de Portugal: desde o começo da monarchia até o fim do reinado de Affonso III. 8. ed. Lisboa: Bertrand, 1875. t. I.

MATOS, Sérgio Campos. História e identidade nacional - A formação de Portugal na historiografia contemporânea. Lusotopie, v. 2, p. 123-139, 2002.

MATTOSO, José. Prefácio. In: HERCULANO, A. História de Portugal: desde o começo da Monarquia até ao fim do Reinado de Afonso III. Lisboa: Bertrand Editora, 2007, p. 9-31.

MAURÍCIO, Carlos. A invenção de Oliveira Martin: política, historiografia e identidade nacional no Portugal contemporâneo (1867-1960). Lisboa: Imprensa Nacional/Casa da Moeda, 2005.

NEMÉSIO, Vitorino. A mocidade de Herculano até a volta do exilio (18101832). Lisboa: Imprensa Nacional/Casa da Moeda, 2003.

SANTOS, Mariana A. Machado. Alexandre Herculano e a Biblioteca da Ajuda. 0 Instituto, v. CXXVII, p. 1-80, 1965.

SARAIVA. Herculano e o Liberalismo em Portugal. Amadora: Bertrand, 1977.

SERRÃO, Joaquim Veríssimo. Herculano e a consciência do liberalismo português. Lisboa: Livraria Bertrand, 1977.

SKINNER, Quentin. Visões da política: sobre os métodos históricos. Algés: Difel, 2005. 